Supplement of Hydrol. Earth Syst. Sci., 25, 473-495, 2021

https://doi.org/10.5194/hess-25-473-2021-supplement

(C) Author(s) 2021. This work is distributed under

the Creative Commons Attribution 4.0 License.

(c) (i)

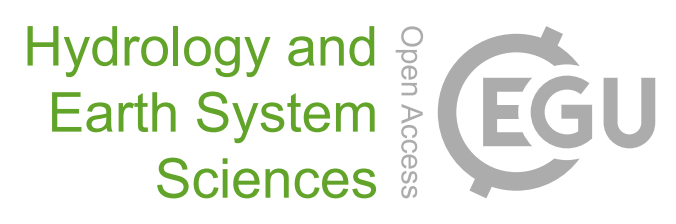

Supplement of

\title{
Validation of SMAP L2 passive-only soil moisture products using upscaled in situ measurements collected in Twente, the Netherlands
}

Rogier van der Velde et al.

Correspondence to: Rogier van der Velde (r.vandervelde@utwente.nl)

The copyright of individual parts of the supplement might differ from the CC BY 4.0 License. 
Table

Table S1: Vegetation cover, sensor depth and type, and dates on which changes were made in the location of the monitoring stations that were operational in the Twente network from January 2015 up to March 2019. Note that when the description indicates that the station was equipped with 5TM sensors after a specific date, it means that EC-TM sensors were active before.

\section{$5 \quad$ List of Figures}

Figure S1. Same as Fig. 8 except for reference pixel 3306.

Figure S2. Same as Fig. 8 except for reference pixel 4371.

Figure S3. Scatter plots of morning SMAP soil moisture retrievals for reference pixel 3606 versus in situ references, a), b), and c) indicate SMAP estimates derived using SCA-H, SCA-V and DCA, respectively; i) holds as reference the unbiased 7-station mean,

10 ii) holds as reference the all station mean, iii) holds as reference model-all spatially scaled version of $i$, iv) holds as reference modelall spatially scaled version of ii, v) holds as reference model-pdf1 spatially scaled version of i, iv) holds as reference model-pdf1 spatially scaled version of ii.

Figure S4. Same as Fig. S3 except that the scatter plots are showing the afternoon SMAP soil moisture retrievals for reference pixel 3606.

15 Figure S5. Same as Fig. S3 except that the scatter plots are showing the morning SMAP soil moisture retrievals for reference pixel 3306.

Figure S6. Same as Fig. S3 except that the scatter plots are showing the afternoon SMAP soil moisture retrievals for reference pixel 3306.

Figure S7. Same as Fig. S3 except that the scatter plots are showing the morning SMAP soil moisture retrievals for reference pixel 4371.

Figure S8. Same as Fig. S3 except that the scatter plots are showing the afternoon SMAP soil moisture retrievals for reference pixel 4371. 
Table S1: Vegetation cover, sensor depth and type, and dates on which changes were made in the location of the monitoring stations that were operational in the Twente network from January 2015 up to March 2019. Note that when the description indicates that the station was equipped with 5TM sensors after a specific date, it means that EC-TM sensors were active before.

\begin{tabular}{|c|c|c|c|}
\hline Station ID & Vegetation cover & $\begin{array}{l}\text { Sensor depth (in } \mathrm{cm}) \text { and type in } \\
\text { parenthesis () }\end{array}$ & Location changes \\
\hline ITCSM01 & grassland & $5,10,20,40(5 \mathrm{TM})$ & \\
\hline ITCSM02 & grassland/maize & $\begin{array}{l}5(5 \mathrm{TM} \text { as of } 8-4-2015), 10(5 \mathrm{TM} \text { as of } 8-7- \\
2016), 20,40(5 \mathrm{TM} \text { as of } 8-4-2015)\end{array}$ & \\
\hline ITCSM03 & grassland & 5, 10 (5TM), 20, 40, 80 (since $2-5-2017,5 \mathrm{TM})$ & 2-5-2017: reinstalled \\
\hline ITCSM04 & grassland & $5,10,20(5 \mathrm{TM}$ as of 9-3-2016) & 9-3-2016: reinstalled \\
\hline ITCSM05 & grassland & $\begin{array}{l}5,10,20,40(5 \mathrm{TM} \text { as of } 22-4-2016), 80(5 \mathrm{TM}, \\
\text { available from } 2-5-2017)\end{array}$ & $\begin{array}{l}\text { 2-5-2017: installed in another field } \\
\text { 24-5-2018: reinstalled }\end{array}$ \\
\hline ITCSM06 & $\begin{array}{l}\text { rotating crops: maize, } \\
\text { potato }\end{array}$ & $5,10,20,40,80(5 \mathrm{TM})$ & $\begin{array}{l}\text { 20-5-2016: reinstalled } \\
\text { 29-8-2017: stopped }\end{array}$ \\
\hline ITCSM07 & $\begin{array}{l}\text { rotating crops: maize, } \\
\text { wheat }\end{array}$ & $5,10,20,40(5 \mathrm{TM})$ & 3-11-2015: reinstalled \\
\hline ITCSM08 & maize & $5,10,20,40$ (5TM since $22-4-2016)$ & \\
\hline ITCSM09 & $\begin{array}{l}\text { rotating crops: maize, } \\
\text { wheat }\end{array}$ & $5,10,20,40(5 \mathrm{TM})$ & \\
\hline ITCSM10 & $\begin{array}{l}\text { rotating crops: wheat, } \\
\text { maize, potato }\end{array}$ & $5,10,20,40,80(5 \mathrm{TM}$ since $20-5-2016)$ & 20-5-2016: installed in another field \\
\hline ITCSM10 & grassland & $\begin{array}{l}5,10,20,40(5 \mathrm{TM} \text { since } 9-10-2015), 80(5 \mathrm{TM} \\
\text { since } 18-10-2016)\end{array}$ & 18-10-2016: installed in another field \\
\hline ITCSM12 & grassland & $5,10,20,40(5 \mathrm{TM}$ since $16-4-2015)$ & \\
\hline ITCSM13 & grassland & $5,10,20,40(5 \mathrm{TM})$ & \\
\hline ITCSM14 & grassland & $5,10,20,40(5 \mathrm{TM}), 80$ (5TM since 1-4-2016) & 1-4-2016: installed in another field \\
\hline ITCSM15 & grassland & $\begin{array}{l}5,10,20,(5 \mathrm{TM} \text { since 7-3-2016) 40, } 80 \text { (5TM, } \\
\text { available from 7-3-2016) }\end{array}$ & 7-3-2016: reinstalled \\
\hline ITCSM16 & grassland & $5,10(5 \mathrm{TM})$ & \\
\hline ITCSM17 & grassland & $\begin{array}{l}5,10(5 \mathrm{TM}), 20,40,80 \text { (5TM, available from } \\
1-4-2016)\end{array}$ & 1-4-2016: reinstalled \\
\hline ITCSM18 & grassland/maize & $5,10,20,40(5 \mathrm{TM}$ since $17-4-2015)$ & \\
\hline ITCSM19 & grassland & $5,10,20,40(5 \mathrm{TM})$ & 20-9-2017: stopped \\
\hline ITCSM20 & forest & $5,10,20,40(5 \mathrm{TM})$ & 31-12-2016: stopped \\
\hline Hupsel & grassland & $5,10,20,40,80(5 \mathrm{TM})$ & 20-12-2017: installed \\
\hline Twenthe & natural pasture & $5,10,20,40,80(5 \mathrm{TM})$ & 20-12-2017: installed \\
\hline
\end{tabular}




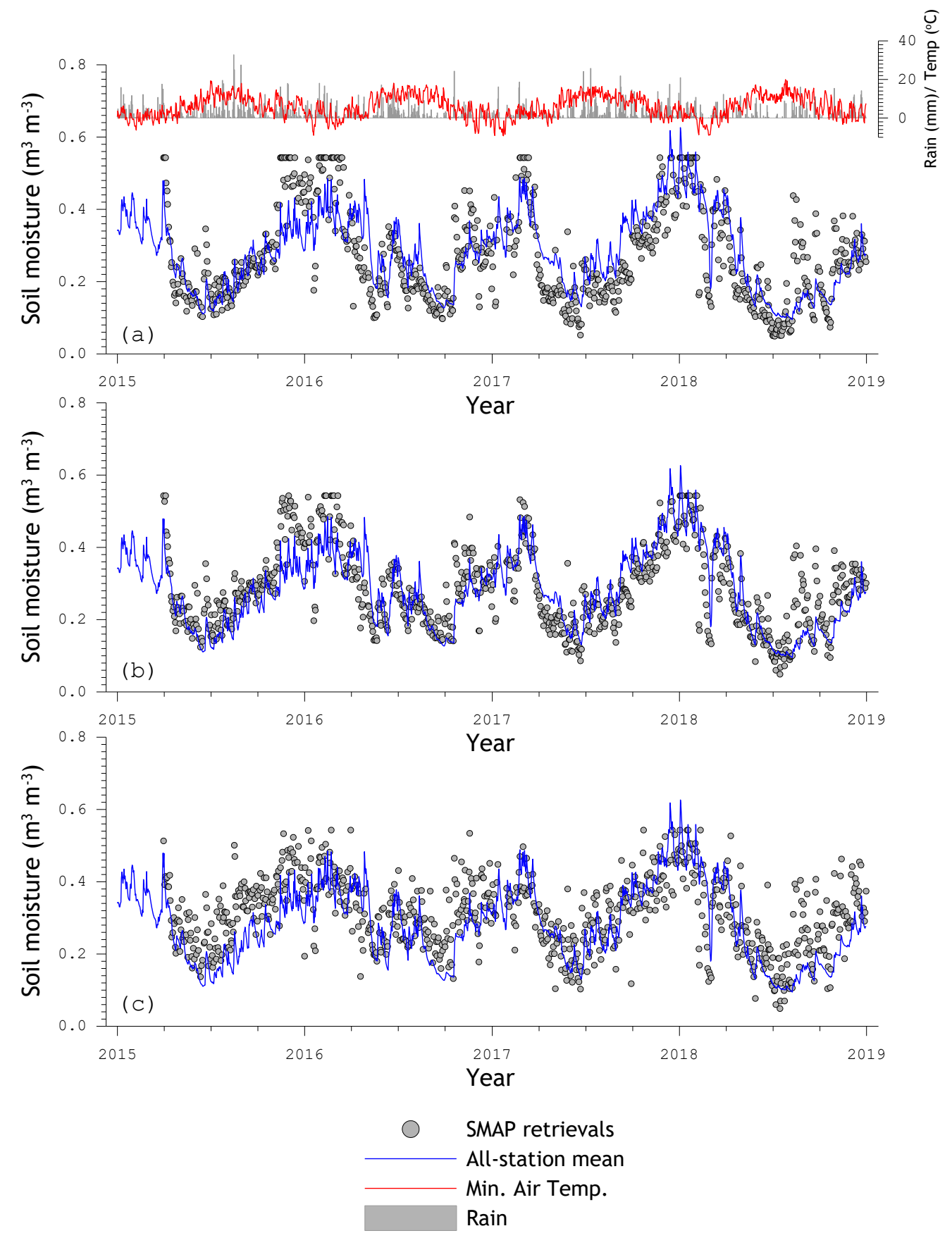

Figure S1. Same as Fig. 8 except for reference pixel 3306. 


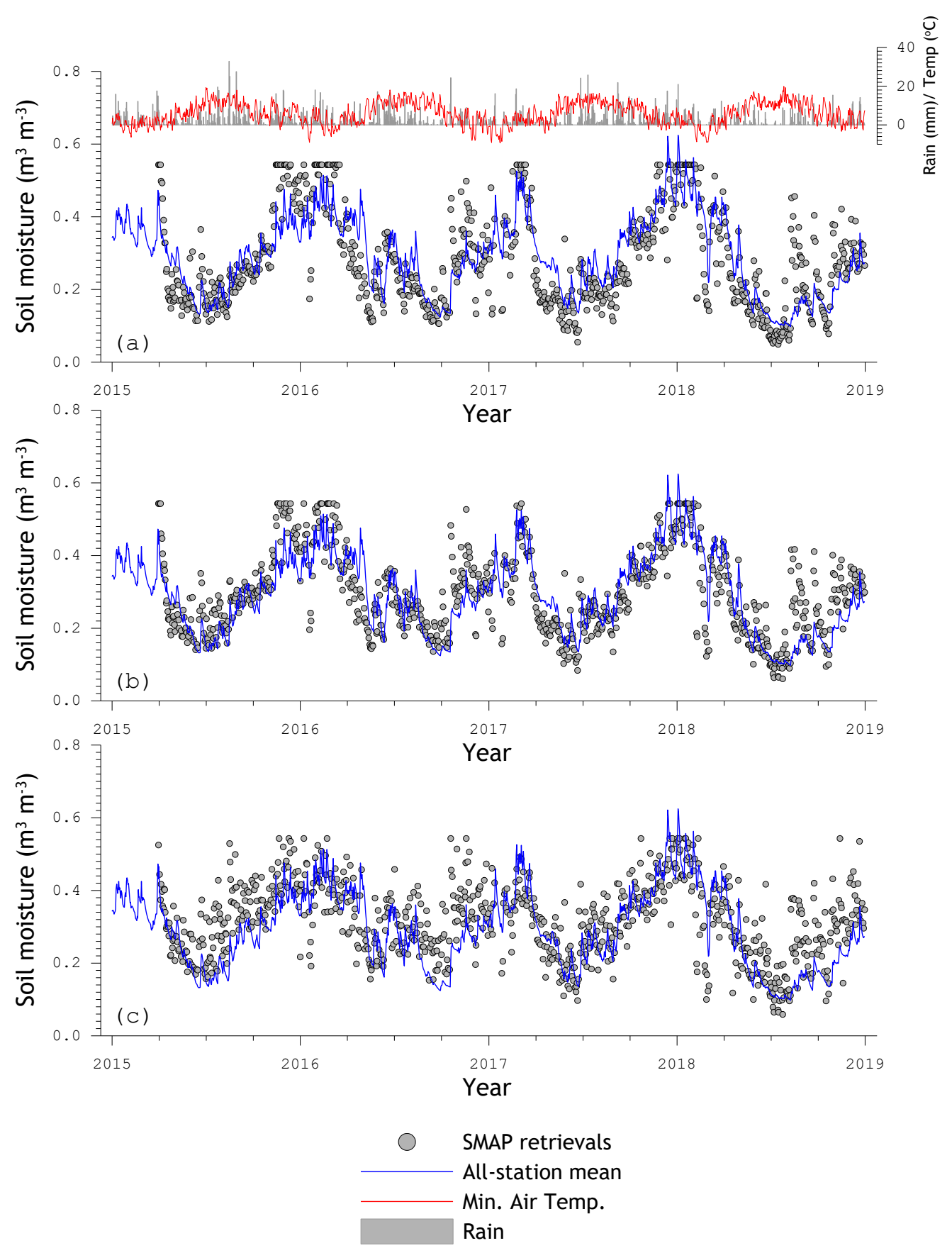

Figure S2. Same as Fig. 8 except for reference pixel 4371. 

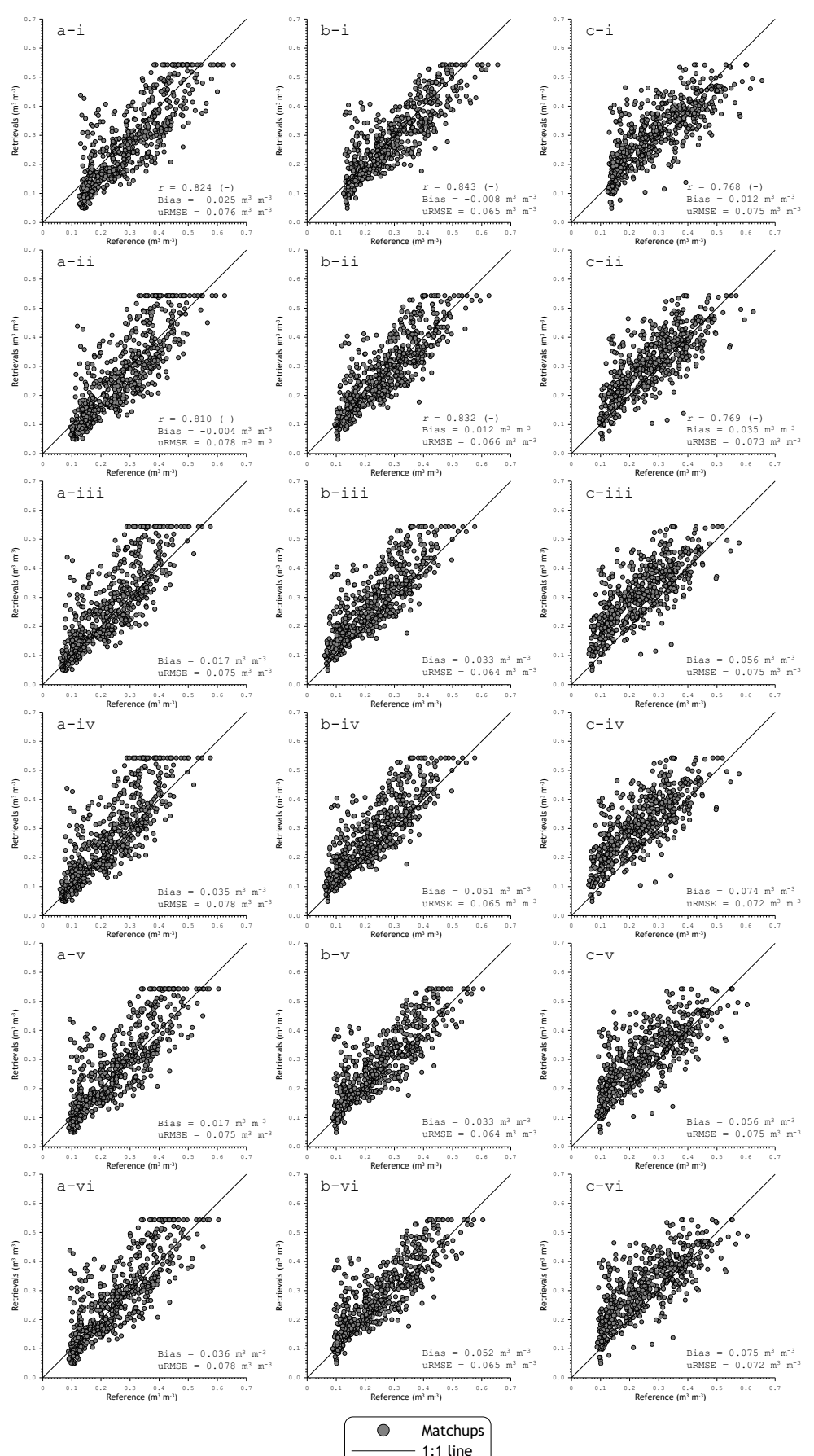

Figure S3. Scatter plots of morning SMAP soil moisture retrievals for reference pixel 3606 versus in situ references, a), b), and c) indicate SMAP estimates derived using SCA-H, SCA-V and DCA, respectively; i) holds as reference the unbiased 7-station mean, ii) holds as reference the all station mean, iii) holds as reference model-all spatially scaled version of $i$, iv) holds as reference modelall spatially scaled version of ii, v) holds as reference model-pdf1 spatially scaled version of i, iv) holds as reference model-pdf1 5 spatially scaled version of ii. 


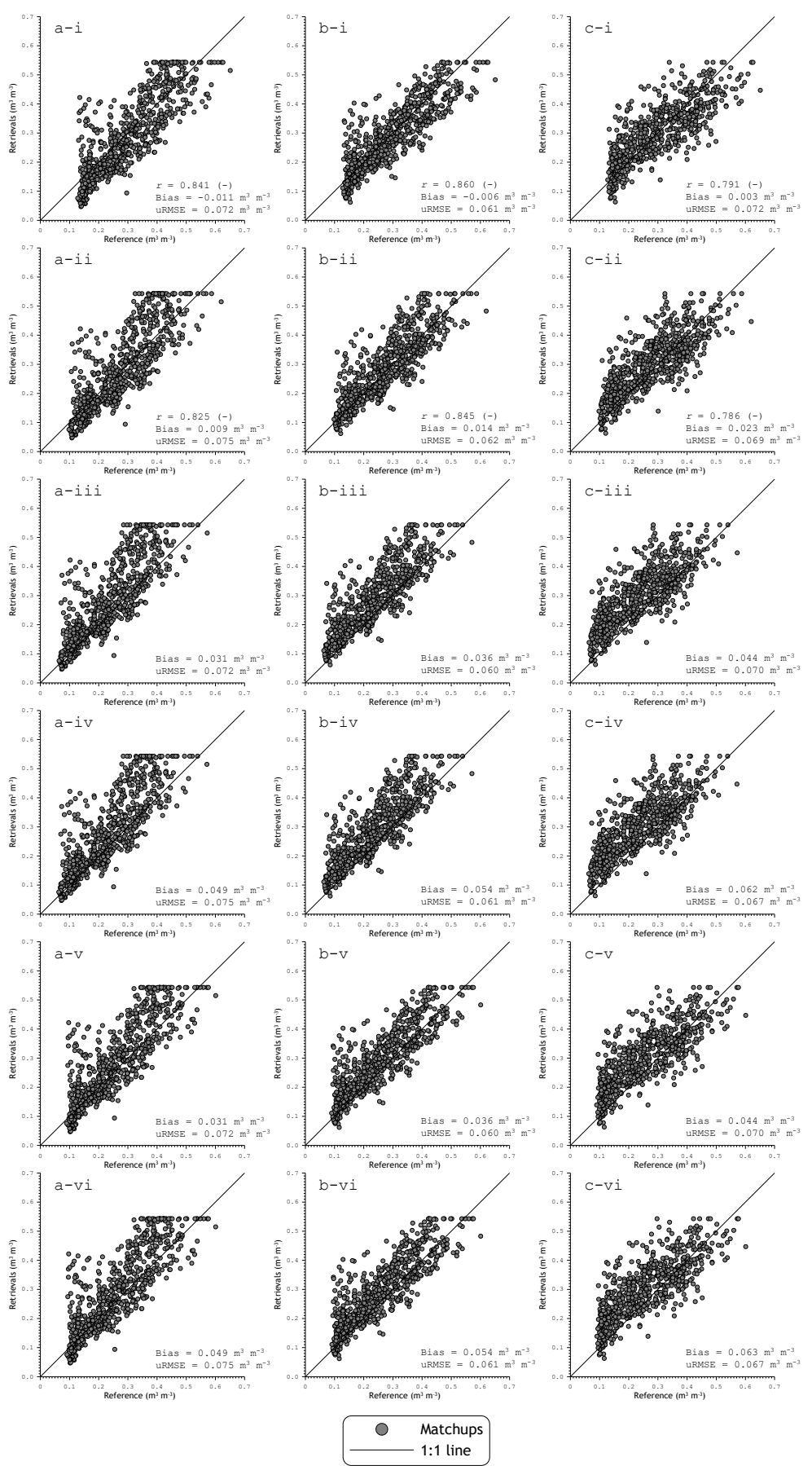

Figure S4. Same as Fig. S3 except that the scatter plots are showing the afternoon SMAP soil moisture retrievals for reference pixel 3606. 

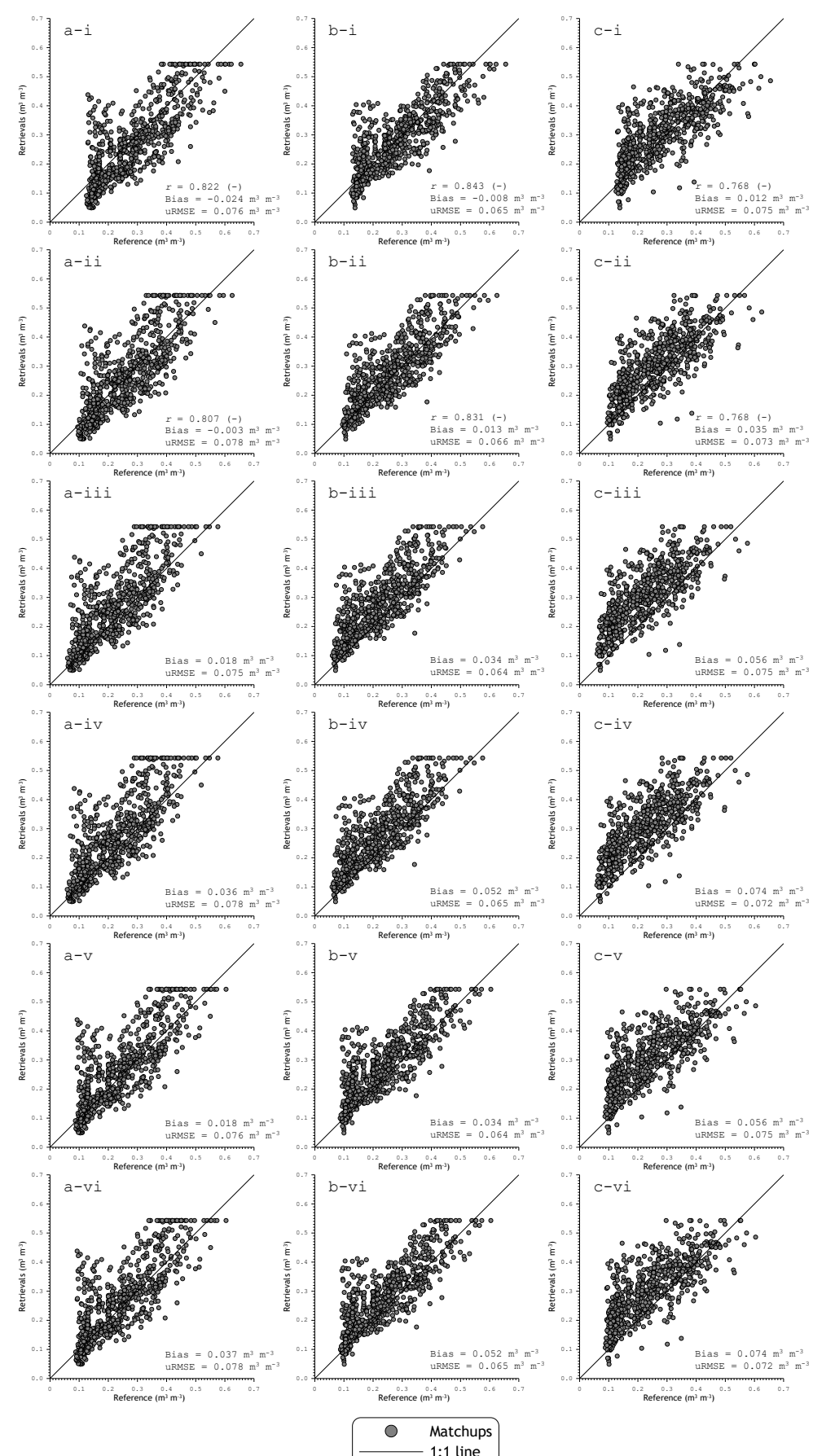

Figure S5. Same as Fig. S3 except that the scatter plots are showing the morning SMAP soil moisture retrievals for reference pixel 3306 . 


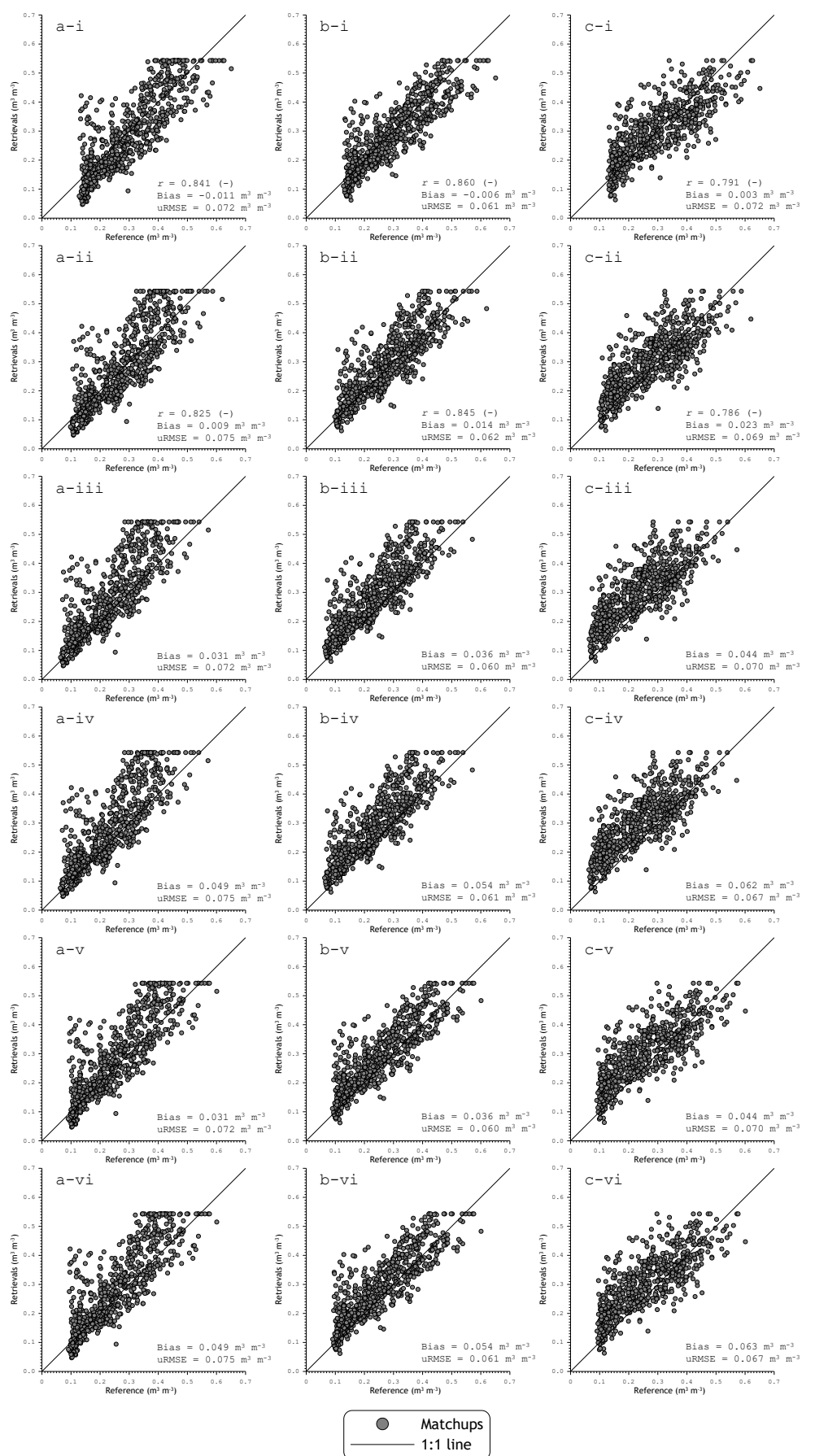

Figure S6. Same as Fig. S3 except that the scatter plots are showing the afternoon SMAP soil moisture retrievals for reference pixel 3306. 


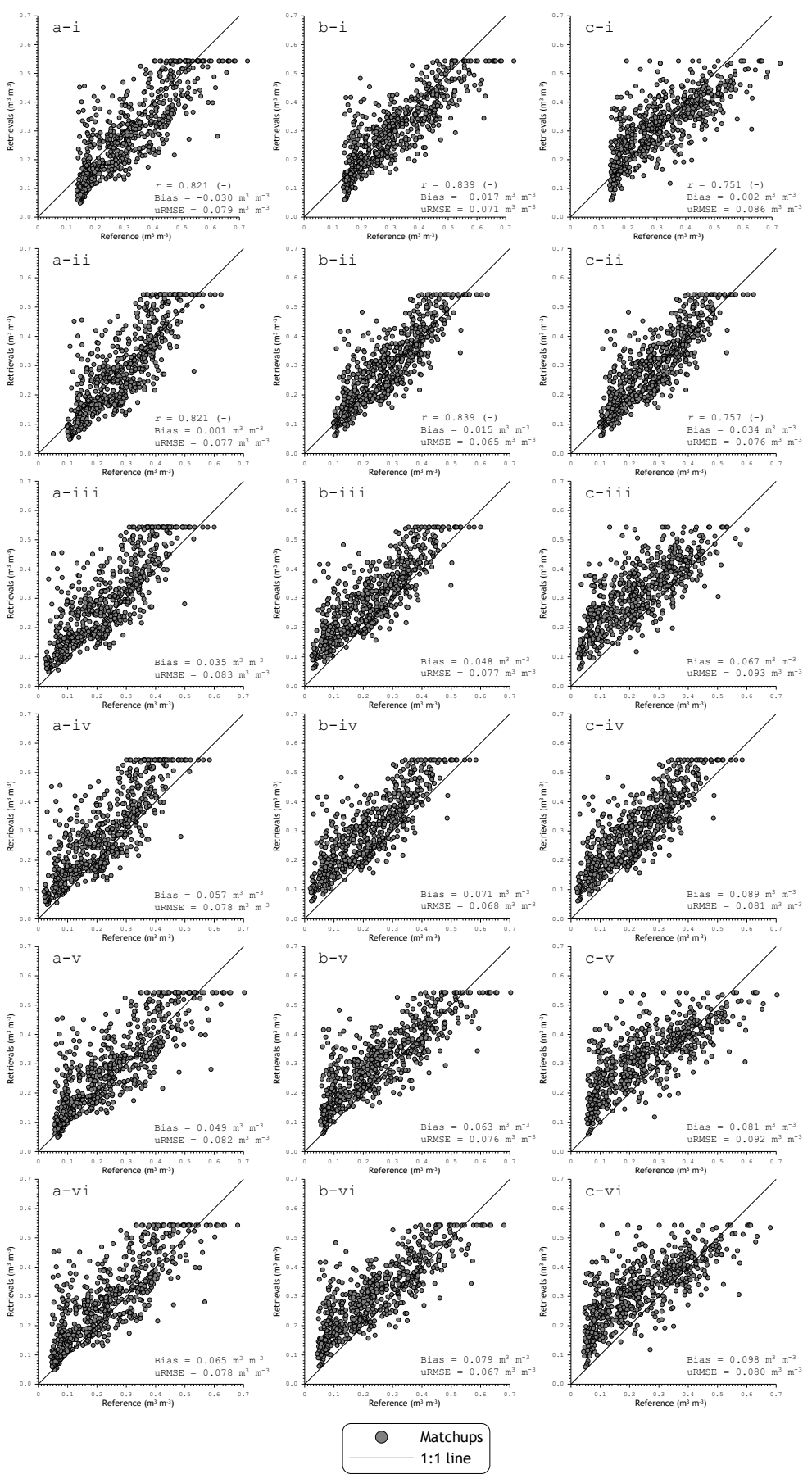

Figure S7. Same as Fig. S3 except that the scatter plots are showing the morning SMAP soil moisture retrievals for reference pixel 4371. 

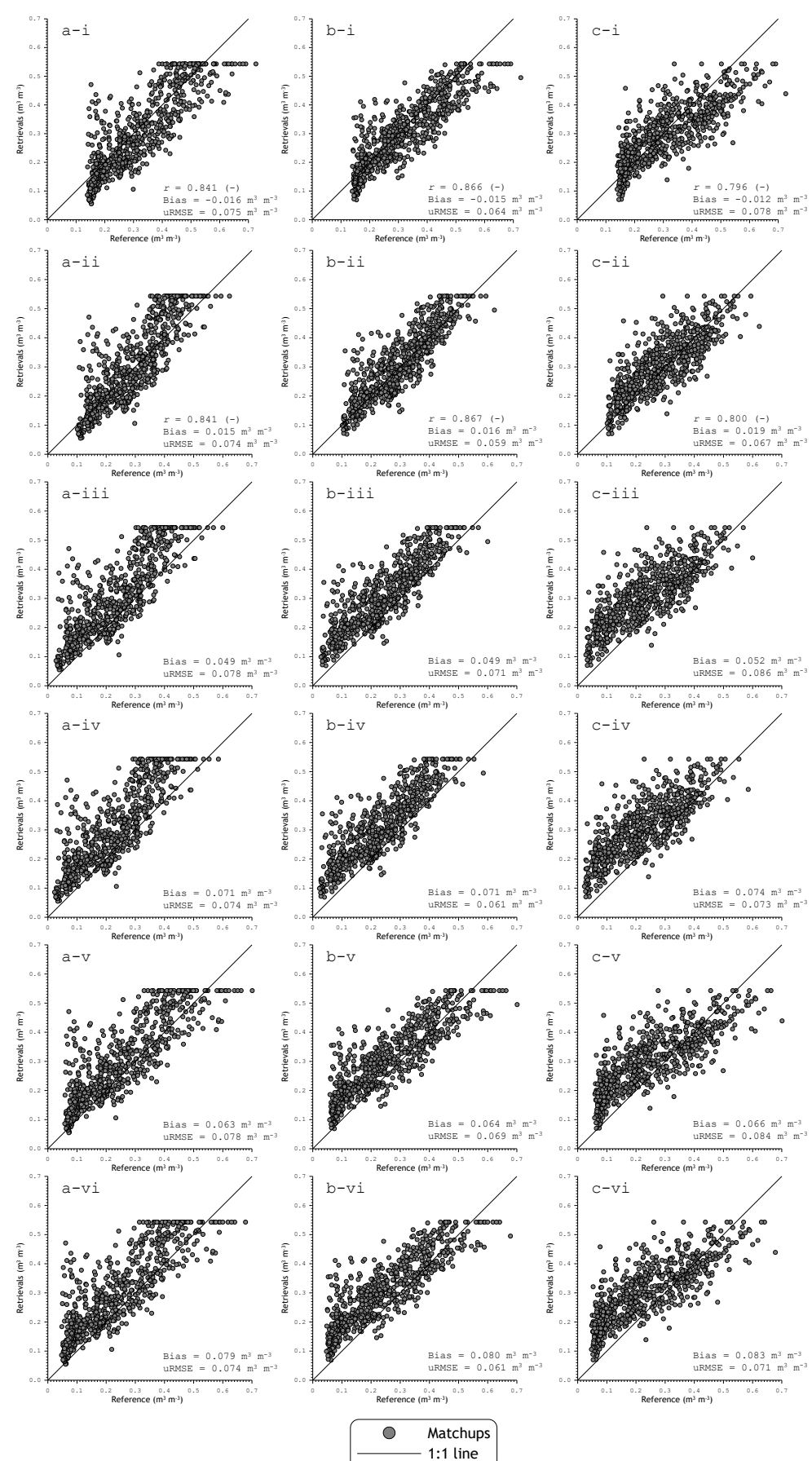

Figure S8. Same as Fig. S3 except that the scatter plots are showing the afternoon SMAP soil moisture retrievals for reference pixel 4371. 